\title{
LA CONSTRUCCIÓN DE LA IMAGEN DEL DERECHO: UN RECORRIDO HISTÓRICO*
}

\author{
Ana Laura NETTEL D.
}

\begin{abstract}
Resumen:
La idea central de este ensayo es que las imágenes visuales del derecho han contribuido en un modo importante a la creación de una imagen mental del derecho que apoya la creencia de que hay una obligación de obedecer el derecho. Así, el propósito de la autora es: primero, identificar y analizar la representación visual del derecho y los mensajes que ellas transmiten. Segundo, tratar de averiguar cómo estas representaciones conforman la imagen mental que tenemos del derecho: siguiendo la distribución del espacio judicial y, entonces, a través de la iconografía del derecho para comprender cómo construyen la creencia de que hay una obligación de obedecer el derecho; y por lo tanto la idea de que el derecho tiene una autoridad.
\end{abstract}

Abstract:

The idea that guides this paper is that visual images of law have contributed in a very important way to the creation of a mental image of law that supports the belief in an obligation to obey the law. My purpose is: first, to identify and to analyse the visual representation of law and the messages they convey. Second, attempt to find out how they shape the mental image we have of law by following the construction of judicial space and, then, through the iconography of law in order to understand how they build the belief that there is an obligation to obey the law; hence the idea that law has authority.

* El presente artículo fue previamente publicado en inglés por el mismo Instituto de Investigaciones Jurídicas de la UNAM bajo el título "The Power of Image and the Image of Power. The Case of Law", en las memorias del Primer Congreso Internacional de Culturas y sistemas Jurídicos Comparados, véase Cáceres, Enrique et al. (coords.), Problemas Contemporáneos de la Filosofía del Derecho, México, UNAM, Instituto de Investigaciones Jurídicas, 2005. 
ANA LAURA NETTEL D.

SUMARIO: I. Introducción. II. La sacralización del espacio. III. El enlace entre Dios y la autoridad del derecho. IV. Símbolos y la relación entre derecho y justicia. V. ¿Cuál es el poder de la imagen, qué podemos hacer con las imágenes?

\section{INTRODUCCIÓN}

El análisis de la iconografía del derecho nos llevará de una manera realista, creo yo, a la comprensión del tipo de autoridad que reivindica el derecho y, en consecuencia, a la de la naturaleza de su pretensión de autoridad. Esto no debe entonces confundirse con la muy debatida cuestión acerca de cuáles son las condiciones de legitimidad de la autoridad.

Procederé, primero, a analizar algunas las representaciones del derecho y los mensajes que éstas transmiten y, segundo, a tratar de descubrir cómo éstas dan forma a la imagen mental ${ }^{1}$ que tenemos del derecho; lo haré siguiendo la construcción del espacio judicial y, luego, a través de la iconografía del derecho.

Sin embargo, en la medida en que voy a recorrer varios periodos y lugares (varios países europeos), se impone una justificación de la variedad del material elegido. La cultura occidental tiene una unidad que viene principalmente de su común origen latino ${ }^{2}$ y judeo-cristiano. Esa unidad me permite tomar ejemplos de diferentes fuentes y periodos europeos para hacer proposiciones generales acerca de dicha cultura.

Sería una tarea gigantesca dar cuenta de manera completa del discurso de legitimación del derecho. Una razón es la extensión del periodo. Otra es la diversidad de las formas discursivas: discurso político, por supuesto, pero también medios de comunicación, arte, educación, etcéte-

1 Respecto de la relación entre imagen mental, imagen visual y representación véase Denis, M., Image et cognition, París, PUF, 1989.

2 Véase el libro clásico de Curtius, E. R., European Literature and the Latin Middle Ages, Nueva York, Panthéon Books, 1953. 
ra. Me limitaré al análisis de los mensajes transmitidos por algunas imágenes visuales entre los siglos XIII y XVIII principalmente. ${ }^{3}$

Este trabajo trata de responder a las siguientes preguntas ¿qué hace creer a la gente que existe una obligación de obedecer el derecho?, ¿de qué manera se consideró tan natural esta creencia que para la mayoría de la gente hacerse esta pregunta apenas tiene sentido?, ¿cuál es el mensaje inscrito en la cultura occidental que produce esta creencia?

La pregunta acerca de la naturaleza de la autoridad del derecho está presente el toda la historia de la filosofía jurídica. Así, la pretensión de este trabajo es precisamente mostrar cómo funciona la creencia en la obligación de obedecer el derecho.

Mi interés se centra en la autoridad del derecho en tanto producto de la cultura occidental. Se trata de una organización normativa que tiene un discurso justificador, una respuesta a la pregunta fundamental: ¿cuál es la razón de la existencia del derecho? O en otras palabras ¿en qué tipo de argumentos se funda el derecho para justificar su autoridad?

Es un lugar común que vivimos rodeados de imágenes y que éstas tienen una gran importancia en nuestra vida; por ello parece interesante dirigir los reflectores al papel que las imágenes juegan en nuestra percepción del derecho. Este enfoque busca entender la manera en que el derecho ejerce autoridad sobre nosotros.

\section{SACRALIZACIÓN DEL ESPACIO}

El árbol ha sido utilizado casi universalmente para simbolizar la relación entre el cielo y la tierra. Culturas tan dis-

3 Las imágenes que analizo en este trabajo vienen principalmente de Jacob's Robert, Images de la Justice, París, Le Léopard d'Or, 1994, y Ribner's, Jonathan P., Broken Tablets: The Cult of Law in French Art from David to Delacroix, Berkeley, University of California Press, 1993. Para una presentación general del tema, $c f r$. Law and the Image (coordinado por C. Douzinas and L. Nead), Chicago, Chicago University Press, 1999. 
tantes como la celta, la escandinava y las indígenas de Norteamérica entre otras, han usado, de manera similar, el árbol para representar el eje que relaciona lo natural con lo supra-natural, funcionando como un canal de comunicación entre la divinidad y el hombre. Los celtas solian juzgar debajo de un roble, los escandinavos debajo de un fresno y los germanos debajo de un tilo. ${ }^{4}$

Podemos todavía encontrar árboles viejos como el tilo de Bordesholm, Schleswig-Holstein, utilizado en el siglo XV con este propósito. Otro caso muy famoso, por lo menos en Francia, es el de San Luis, quien juzgaba debajo de un roble. En la Cour de Cassation de París hay una escultura de Eugène Guillaume basada en un dibujo de Duc (18771878) en el cual, recordándonos este hecho, San Luis de Francia está representado juzgando debajo de un roble. El papel de los árboles como enlace entre los hombres y Dios está también presente en la iconografía inglesa; un ejemplo es el frontispicio de Los oráculos de los pastores de Francis Quarles (1645) que muestra a Carlos Primero defendiendo el árbol de la religión. ${ }^{5}$ En medio de la escena hay un árbol flanqueado por dos personajes de la iglesia; las ramas del árbol representan las virtudes: fe, esperanza, caridad y obediencia. A la derecha podemos ver a Carlos Primero blandir una espada reforzada por otra espada más grande que se encuentra en la parte superior derecha de la imagen, significando que Dios también está en ese combate.

Más tarde una columna sustituirá el árbol. ${ }^{6}$ Se trata de columnas de piedra llamadas Columna del Mundo o Colum-

4 Véase Jacob, R., Images de la justice, cit., nota 3, pp. 39 y ss.; también "The Entry "Arbre", en Chevalier, J. y Gheerbrant, A. (eds.), Dictionnaire des symboles, París, Laffont, 1982, pp. 62 y ss.

5 Reproducido en Philippe, R., Affiches et caricatures dans l'histoire, París, Fernand Nathan, 1981, p. 77.

6 Sobre esta sustitución, véase Jacob, R., Images de la justice, cit., nota 3, p. 44; la sustitución del árbol por una columna está presente en el arte del Renacimiento; véase en particular Francastel, F., Peinture et société, Lión, Audin, 1951, p. 61. 
na de la Justicia, como la del siglo X que se encuentra en el mercado de Treves. ${ }^{7}$

Muchas mitos asocian a Dios con el juicio porque es por definición Él que ve y sabe todo, en consecuencia es el único ser capaz de justicia. Al juzgar debajo de un árbol se da la idea de que los jueces son simples intermediarios de la divinidad, de tal suerte que mientras juzgan actúan fuera de su condición de hombres. Esta idea se refuerza extrayendo el acto del juicio del espacio de la vida cotidiana, es decir, llevándolo acabo en un lugar exterior a los muros de la ciudad; lugar que se delimita además con una valla para indicar su carácter especial. Así, el acto de juzgar - una tarea divina por excelencia - se lleva acabo fuera del espacio profano de las preocupaciones humanas. Sacralizando el espacio del juicio se transmite el mensaje de la naturaleza trascendental del derecho y por consiguiente se justifica la exigencia del cumplimiento de sus mandatos. ${ }^{8}$

Una miniatura de 1513 de una sesión extramuros del tribunal de Mulhouse es una bellísima ilustración de los elementos utilizados para la sacralización de los espacios judiciales. Vale la pena recordar que hasta a principios de la Edad Media, la resolución de los conflictos era negociada entre las partes y que solamente a fines de la Edad Media se creó una institución para estos propósitos. ${ }^{9}$

La naturaleza sagrada del lugar de los juicios, y por consiguiente del acto de juzgar, se mantiene todavía hoy en día en la organización del espacio de las Cortes, en éstas encontramos a menudo una barra separando el espacio del público del juicio. A veces en las imágenes del siglo XVIII, una sala grande estaba simplemente dividida por una barandilla que separaba a los espectadores de los que participaban en el proceso. Un ejemplo es un gravado holandés de

7 Para el significado general de las columnas véase Onians, J., "The Strength of Columns and the Weakness of Theory", en Scott, S. C. (coord.), The Art of Interpreting, University Park, Pennsylvania University Press, 1995, pp. 30-39.

8 Cfr. Eliade, M., Le Sacré et le profane, París, 1965.

9 Foucault, Michel, La verdad y las formas jurídicas, 2a. reimp., México, Gedisa, 1984 . 
aquella época que muestra cómo estaba ubicado el lugar del juicio en una Corte. ${ }^{10}$ Otra reminiscencia del recinto cerrado es el término "barra" de abogados. El primer significado (de 1339) del término francés para barra, "parquet" es pequeño parque. En el siglo XIV designaba el lugar en donde los jueces y los abogados se ubicaban en una Corte. Hoy en día, "barre" o "barreau" es una metonimia para designar la oficina del procurador de justicia con el término "parquet”.

Un pintura de Schopin encargada en 1844 por la Cámara de Comercio de Rouen representa un juramento, como tantas otras pinturas de esa época. La obra de Schopin describe el juramento de los primeros jueces consulares en Rouen en 1563. Esta imagen describe una variante del recinto consistente en una barra formada por pilares que todavía encontramos hoy en día en la arquitectura judicial. Algunas veces la naturaleza sagrada del acto de juzgar está también señalada por una diferencia de altura. El juez está normalmente sentado en un sitial a mayor altura, desde el cual se domina la escena donde los abogados presentan sus argumentos. En un nivel más bajo, un lugar especial, está destinado a quienes están bajo juramento.

La frecuente representación de juramentos constituye otro elemento muy utilizado para indicar el carácter trascendental del derecho. Como todos sabemos, el juramento tiene todavía, aun en sociedades laicas, gran relevancia en el procedimiento. La presencia de juramentos en las representaciones del derecho comienza a finales del siglo XV. En una crónica de Diebold Schilling se encuentra una representación de El juramento de la damas de Bubenberg, éste forma parte del acervo de la biblioteca municipal de Berna.

La arquitectura monumental de los edificios judiciales y legislativos constituye otra manera de transmitir visualmente el mensaje de la autoridad del derecho. En cada capital que visitamos siempre nos sentimos impresionados

10 Gravado reproducido en Jacob's, Robert, Images de la Justice, París, Le Léopard d'Or, 1994, p. 96. 
por los edificios de los poderes Judicial y Legislativo. Todos ellos comparten una arquitectura grandiosa concebida para transmitir la idea de un poder omnipotente. ${ }^{11}$

\section{El ENLACE ENTRE Dios Y LA AUTORIDAD DEL DERECHO}

Ciertamente no es una idea nueva el que, durante la Edad Media, se consideraba que la fuente de la autoridad era divina. Sin embargo, lo que me parece importante es poner énfasis en la manera en que funciona el enlace entre Dios y la autoridad política, y cómo este enlace dio lugar a una larga cadena de argumentos, presente hoy en día, debido a conexiones menos conocidas que producen en nuestra imaginación la convicción de la relación del derecho con Dios. ${ }^{12}$

La primera imagen que quiero considerar viene de una copia del siglo XIII del Decreto Graciano (libro del derecho canónico): la investidura de los poderes espiritual y temporal hecha por Cristo. ${ }^{13}$ La escena está organizada por una $H$ mayúscula situada en el medio y que simboliza al género humano, esta inicia la primera subdivisión del libro: la humanidad es gobernada por dos tipos de normas: el derecho natural y la costumbre. Esta subdivisión muy pronto se hizo una convención, un código fijo. Mas lo que es importante es el mensaje: el poder espiritual viene directamente de Dios, por supuesto, pero también el poder temporal. Esto llegará a ser el tema más importante y constante de la imagen del derecho. Varias son las formas en que se establece esta relación: a veces, los representantes de ambos

11 Cfr. Le gigantesque, número especial de Comunications, núm. 42, 1985. Sobre la arquitectura judicial véase, en particular, el volumen colectivo publicado por la Asociación Francesa para la Historia de la Justicia, La Justice en ses temples, París, Erance, 1992, así como parte III de Law and the Image (ed. by C. Douzinas and L. Neal), cit., nota 3, pp. 117 y ss.

12 La relación entre la trascendencia y el derecho ha sido sostenida por P. Legendre en Le désir politique de Dieu: Etude sur les montages de l'Etat et du droit, París, Fayard, 1988; la relación a las imágenes ha sido profundizada en Dieu au miroir: Etude sur l'institution des images, París, Fayard, 1994.

13 Biblioteca Nacional de Beaune. 
poderes comparten el bastón de mando. En otros casos, encontramos también una o más llaves entregadas al poder espiritual, mientras una espada es dada al poder temporal; o una espada a cada uno de los poderes. En la iconografía del siglo XIV se usaba la espada para el orden tanto espiritual como temporal. El símbolo de la espada sigue jugando, hasta la fecha, un papel muy importante en la iconografía del derecho. Lo que debemos tener presente es que este simbolo supuestamente viene directamente de Dios.

Este tipo de representación es común a los Decretos Gracianos en toda Europa, así como al Espejo Sajón (Sachensspiegel), mismos que constituyen las obras más conocidas y apreciadas de la literatura judicial desde la Edad Media, y en consecuencia las más copiadas en esa época. El tema de una imagen del siglo XIII del Decreto Graciano que se encuentra en la biblioteca pública de la ciudad francesa de Troyes, también son los poderes espiritual y temporal; sin embargo, en este caso, se hizo uso de un recurso retórico muy interesante. Para mostrar la conexión entre ambos poderes, el artista representó la continuidad entre ellos por medio de la continuidad visual de los Diez Mandamientos que se despliegan de uno a otro poder.

En representaciones tempranas de juicios, también encontramos, cuatro niveles de poder relacionado por una vertical. Es el caso en particular de una miniatura italiana del siglo XIV, llamada el Tribunal del Mundo, ${ }^{14}$ el tema de la investidura de los poderes espiritual y temporal está puesto en evidencia en esta obra a través de la espada del rey: poder judicial, religioso, político y, por supuesto, divino. Dios el padre se encuentra arriba con las llaves del cielo en una mano y en la otra un libro que podría ser la Biblia.

"La justicia humana sancionada por Cristo" podría ser el título de la una pintura de la escuela alemana (principios del siglo XV en Wurzbourg, Bisch Fliches Ordinarial). Un caso es llevado ante un juez sentado en un sitial, que es

14 De un ejemplar del Decreto Graciano, iluminación italiana del siglo XVI, Biblioteca pública de Ginebra, reproducida en Images de la Justice, cit., nota 3, pl. III. 
uno de los símbolos de la autoridad, constantemente presente, en subsecuentes imágenes de la justicia. Cristo está sentado arriba con dos espadas dirigidas hacia los oídos, representando de nuevo ambos poderes: espiritual y terrenal. La espada, como hemos dicho antes, un simbolo importante del poder en muchas tradiciones, en el mundo judeo-cristiano occidental está relacionada también con los dos atributos de Dios: su poder y su bondad. ${ }^{15}$

Durante el siglo XVI, la presencia de Cristo o de Dios se volvió aún más frecuente en las imágenes de juicios. Esta asociación transmite de nuevo el mismo mensaje implícito: los jueces son simples intermediarios, iluminados por Dios, quienes ejecutan el juicio de Dios en los humanos. En una imagen del siglo XVI, un juez está sentado bajo la mirada del Cristo del Apocalipsis. ${ }^{16}$ Los mismos elementos están en línea vertical: el juicio, el juez en su sitial y arriba de éstos, el elemento trascendental: Cristo en el cielo con su espada.

Es interesante notar que en los gravados de las etapas del procedimiento civil, en el siglo XVII, encontramos de nuevo en la parte superior de la escena una nube representando a Dios con su espada. Sin embargo, aparece algo nuevo: la presencia, rara en esa época, de la balanza. ${ }^{17}$

Hasta aquí he analizado imágenes de una época en la cual la fuente divina del poder político, y por consiguiente del derecho, no se ponía en cuestión. Sin embargo, hemos de preguntarnos si la supresión de la monarquía fundada en la gracia divina implica el abandono de la justificación trascendental de la autoridad del derecho.

La iconografía francesa revolucionaria nos muestra lo contrario. A pesar de una evidente oposición a la supremacía legislativa del rey, la asociación de la divinidad o de las divinidades con el derecho, es decir, la idea de la trascendencia como forma de fundamentar la autoridad del dere-

15 Philon's De cherubin, 21-27; también cfr. la entrada "épée" en Chevalier, J. y Gheerbrant, A. (eds.), Dictionnaire des symboles, cit., nota 4, pp. 407 y ss.

16 Tengler, Urlich, Der neu Layenspiegel, Augsbourg, 1511, fol.34.

17 Cfr. la entrada "balanza" en Dictionnaire des symboles, cit., nota 4, pp. 99 y ss. 
cho, sigue presente constantemente en la iconografía revolucionaria. 18

En el famoso gravado Declaración del los derecho del hombre $y$ del ciudadano, de L. Laurent a partir de una obra de Jean François Lebarbier (1793), podemos ver una representación de dicha declaración escrita sobre unas tablas redondeadas que recuerdan a las de Moisés. En la parte superior de la escena, entre las nubes, se nota el ojo de Dios rodeado por los característicos rayos de luz. Arriba de las dos columnas que enmarcan las tablas, hay dos personificaciones: a la derecha un ángel con un cetro, símbolo de autoridad, y a la izquierda, una personificación de la libertad. En medio de esas tablas se encuentra el haz de lictor, 19 símbolo de autoridad, y en la parte superior está el gorro frigio, símbolo de libertad de los revolucionarios "sans-culottes".

La representación de la declaración de los derechos del hombre y del ciudadano en tablas redondeadas no es el resultado de una casualidad o de la intención del artista: era parte del discurso oficial. En efecto, la Asamblea Legislativa decretó en 1792 que sus insignias tendrian la forma de tablas de la ley. En un grabado de L.-J. Allais, conmemorando el Festival de la unidad y de la indivisibilidad en agosto de 1793, el segundo año de la República francesa, podemos ver a la izquierda la Constitución republicana en forma de tablas de Moisés, emergiendo de una montaña rodeada de rayos de luz. Del lado derecho circundado por signos astrológicos el haz de lictor está coronado por el gorro frigio.

El característico mensaje trascendental de la autoridad del derecho aludiendo a Dios está también presente en el Homenaje a la Asamblea Nacional, un grabado representando la Constitución francesa en forma de pirámide con incrustaciones de retratos de los héroes revolucionarios. ${ }^{20}$ En

18 Cfr. Ribner, Jonathan P., Broken Tablets, cit., nota 3.

19 El lictor era un funcionario romano que precedía a los magistrados llevando un haz de varas con una hacha en el centro.

20 Cfr. Ribner, Jonathan P., Broken Tablets, cit., nota 3, p. 22. 
la parte inferior se ve al pueblo francés alrededor de la pirámide. En la cúspide de ésta, la flor de lis símbolo de la realeza, de la que emana una luz celestial que ilumina toda la escena. Ese grabado se hizo en 1791, es decir, un año antes de la abolición de la monarquía; sin embargo, nos da la oportunidad de preguntarnos ¿si la idea de la voluntad general debe también ser considerada como una fuente trascendental de legitimidad?

\section{SÍMBOLOS Y LA RELACIÓN ENTRE DERECHO Y JUSTICIA}

Después de este recorrido de varios siglos, hemos recogido varios símbolos que siguen siendo asociados hoy en día con las imágenes de la justicia. La justicia es considerada un atributo derivado del juicio perfecto de Dios, en la medida en que Él es el único ser capaz de ver todo. Siendo Dios justo por excelencia, Él es el primer principio al cual se puede recurrir, de acuerdo con la tradición occidental judeocristiana. Al seguir el desarrollo del lenguaje icónico, hemos visto como se pasa de una manera natural de la relación de Dios con el derecho a la asociación del derecho con la justicia, y en consecuencia se incorpora la idea de que es obligatorio obedecer a la ley. ¿Cómo se muestra esto en las representaciones más conocidas de la justicia? La referencia obligada es la obra de Cesare Ripa escrita en italiano en 1597 y traducida al inglés, al francés, al alemán y al español. ${ }^{21}$ Vale la pena hacer notar que la edición original de su Iconología no estaba ilustrada; era una clasificación y descripción de imágenes, lo que Panofsky llamó iconografía. ${ }^{22}$ Sin embargo, la mayoría de las ediciones siguientes de la obra de Ripa vienen ilustradas con una variedad de estilos conformes a la época de la edición.

La alegoría de la justicia de Ripa es una mujer vestida de blanco y vendada de los ojos. En su mano derecha sostiene

\footnotetext{
21 Ripa, C., Iconología (1597), Madrid, Akal, 1987, 2 vols.

22 Panofksy, E., Studies in Iconology, Nueva York, Harper and Row, 1972, p. 3.
} 
un haz de lictor, en la mano izquierda blande un antorcha o una espada y una balanza. En la edición de Hertel (1758-60), la imagen es enriquecida por otros atributos tales como una corona, un cráneo y un perro sentado a sus pies.

De acuerdo con Ripa, este es el tipo de justicia que ejercen los jueces en las cortes. El vestido blanco simboliza el hecho de que los jueces deben ser intachables. La justicia tiene los ojos vendados para simbolizar que no debe ser engañada por los sentidos, pero también que la justicia tiene que usar únicamente la razón mientras juzga, y que la justicia es imparcial. La balanza igualmente, una metáfora de la justicia indica que cada persona debe recibir ni más ni menos que lo que le corresponde.

Desde el punto de vista de la retórica de la imagen, también es muy importante el hecho de que los símbolos utilizados para representar la autoridad de la justicia se repiten constantemente. Primero, la espada blandida que significa aquí el rigor de la justicia que no debe dudar en castigar; segundo, el haz de lictor que era el viejo símbolo romano del poder de los magistrados para mostrar que se debe impartir el castigo; tercero, el cetro símbolo de autoridad por excelencia; y por fin la corona. Todos esos símbolos, como lo hemos visto anteriormente también fueron muy frecuentes en las representaciones de Cristo o de Dios padre. A través de ellos podemos fácilmente seguir algunas de las asociaciones presentes en nuestra percepción de la imagen del derecho, aun si no estamos siempre consientes de ellas.

\section{V. ¿CUÁl ES El PODER DE LA IMAGEN, gUÉ PODEMOS HACER CON LAS IMÁGENES?}

Hasta aquí hemos analizado imágenes que contienen diversas asociaciones que nos llevan al mensaje implícito transmitido por la iconología del derecho. Tratemos ahora 
de encontrar una explicación de la manera en que las imágenes realizan un papel tan importante.

Las imágenes no son simples ilustraciones de lo que pensamos, por lo que el papel que desempeñan no debe ser considerado secundario en la comunicación. ${ }^{23}$ Las imágenes hacen mucho más que ilustrar el discurso verbal, y lo hacen de una manera muy eficaz que corresponde en el lenguaje verbal a un mecanismo al que propuse llamar en otra ocasión el modo implícito. ${ }^{24}$

Entonces, ¿cuál es el poder de las imágenes?25 Para mí, su poder es muy especial, es el poder de "demostración" en el sentido de probar al mostrar. ¿Cómo funciona?

Primero, cuando miramos una imagen frecuentemente tenemos la impresión de estar presente dentro de la escena; la imagen nos ubica en la actitud de un testigo. La razón es probablemente que las imágenes son objetos que nos dan a ver algo. Dicen los abogados que "lo que se ve no se juzga".

Segundo, el poder de las imágenes también viene de la ocultación del acto de la enunciación, o lo que es lo mismo, del hecho de que el narrador no muestra su presencia. A través del análisis de imágenes de varios siglos, hemos subrayado que las imágenes no solo muestran sino que al mismo tiempo demuestran lo que representan. Por ello cuando vemos una imagen, solemos decir para referirnos a ella: "aquí está Cristo invistiendo...”.

En efecto, cuando vemos una imagen, reaccionamos como si no tuviera autor, y tenemos la sensación de que estamos presentes dentro de la escena representada. Pero por el contrario, si frente a una imagen en lugar de mostrar decimos : "aquí, el autor quiere decirnos que...", la actitud del receptor cambia inmediatamente ya que el autor se hace

23 Véase Gombrich, E. H., "The Visual Image: Its Place in Communication", The Image and the Eye, Oxford, Phaidon Press, 1982, pp. 137 y ss.

24 Nettel, A. L. Pouvoir et Légitimité: La stratégie planificatrice au Méxique: 1982-1988, París, l'Harmattan, de próxima aparición.

25 Para dos aproximaciones diferentes, véase Freedberg, D., The Power of Images: Studies in the History and Theory of Response, Chicago, Chicago University Press, 1989, y Marin, L., Des pouvoirs de l'image, París, Seuil, 1993. 
presente. En verdad, en la mayoría de las imágenes, el autor no está, por decirlo así, explícito. ${ }^{26} \mathrm{Es}$ su ausencia la que facilita nuestra capacidad para entrar dentro de la imagen y tener la sensación de que estamos descubriendo lo que vemos, como si estuviéramos ahí. Sólo en ocasiones muy especiales estamos conscientes de la presencia del autor y, asimismo, del hecho de que el autor ha concebido $\mathrm{y}$ realizado la obra con una intención deliberada. Ello ocurre por ejemplo cuando vemos una exposición de pintura. En esas ocasiones, estamos conscientes del hecho de que las pinturas que estamos viendo son la obra de un autor, y es por eso que las vemos como expresando una intención y que las interpretamos en esos términos. Por ello la gente se siente molesta a menudo frente a una que no representa nada, es decir, frente a una obra abstracta.

El tercero y último punto, concierne el hecho de que nuestra actitud más común frente a las imágenes no es crítica. ${ }^{27}$ Esto puede ser por diversas razones: la velocidad con la que tenemos que verlas en ocasiones, por ejemplo, en el metro o cuando estamos manejando, o la capacidad que tiene el creador para hacerlas impactantes. La cuestión es que normalmente cuando vemos una imagen absorbemos el mensaje sin cuestionarlo, es decir, sin la actitud de alguien consciente de estar frente a una proposición. Podría haber múltiples razones como ya dije, pero dos características de las imágenes me parecen muy importantes para explicar esto.

La primera es que las imágenes son transmitidas a nuestra mente, por así decirlo, a través de un canal directo, sin el filtro de la conciencia. En consecuencia, para poder analizar una imagen, y por ende cuestionarla, se necesita un

26 Véase Marin, L., Détruire la peinture, París, Galilée, 1977, pp. 61 y ss., quien muestra que en la pintura representativa clásica hay una denegación del sujeto de la enunciación.

27 Para una diferente aproximación al mismo tema, $c f r$. Douzinas, C., "Prosopon and Antiprosopon: Prolegomena for a Legal Iconology", en Douzinas, C. y Neal, L. (eds.), Law and the Image, cit., nota 3, p. 55. 
grado superior de consciencia que implica un esfuerzo especial de atención y a veces un entrenamiento específico.

La segunda es que las imágenes penetran muy profundamente en nuestra mente porque tomamos lo que vemos en una imagen como una premisa, y consideramos la conclusión a la que somos llevados como nuestra, sin realizar que ésta es la consecuencia que se sigue de la imagen misma. ${ }^{28}$ En esto consiste uno de los principales recursos retóricos de las imágenes. Así, esa actitud no crítica resulta del hecho de que no somos capaces de enfrentarnos con lo que llamo "argumentos pictóricos", 29 es decir, la premisa dada por la imagen y la conclusión que se sigue. Al aceptar lo que vemos en una imagen debido al "efecto de testigo", aceptamos lo que se sigue de ello, siendo el mensaje implícito. De la misma manera que la conclusión a la cual las imágenes visuales nos llevan, los mensajes implícitos son los que no son afirmados pero presupuestos por una proposición. El ejemplo canónico es "Pedro dejó de fumar" cuyo implícito es: "Pedro solía fumar". ${ }^{30} \mathrm{Si}$ aceptamos la primera proposición, también aceptamos automáticamente, por así decir, la segunda. Al decir "Pedro dejó de fumar" no estoy presentando al oyente la proposición: "Pedro solía fumar" la que podría no estar dispuesto a aceptar si la considerara.

Tomando en cuenta la época en la que más he insistido, podríamos concluir que la imagen mental del derecho que he puesto en evidencia sería válida sobre todo desde la Edad Media y el Renacimiento hasta la Revolución francesa. Sin embargo, la mayoría de esos símbolos han sido utilizados después de esa época y lo siguen siendo. Por lo que se refiere al siglo XIX encontramos numerosas representaciones de la imagen de la justicia con forma de Tablas de la

28 Cfr. Miles, M. R., "Image as Insight: Visual Understanding”, Western Christianity and Secular Culture, Boston, Beacon Press, 1985, en particular capítulo 3 "The Evidence of Our Eyes", pp. 41 y ss.

29 Llamo argumentos pictóricos a aquellos que toman en cuenta la parte pragmática de las imágenes visuales.

30 Véase Ducrot, O., Dire et ne pas dire, París, Hermann, 1980, p. 232. 
ley. Entre otros ejemplos podemos mencionar una representación de la justicia del Barón Gérard. Por lo que se refiere al siglo XX el "argumento trascendental" está todavía presente en una pintura hecha por Léon Bonnat, quien fue, sea dicho de paso, el retratista oficial de la Tercera República francesa.

Además del importante papel que han jugado las imágenes (pinturas y esculturas), hay que señalar que en la actualidad la idea de la trascendencia del derecho se transmite sobre todo a través del uso de la monumentalidad en la arquitectura judicial. Por lo que concierne a los libros de derecho, el papel tradicional del frontispicio lo juega hoy en día la portada del libro. Llama la atención la utilización de los símbolos e imágenes analizados en muchos libros recientes. En particular es el caso de la columna, presente en numerosos libros de temas jurídicos, entre los cuales se encuentra el de Marmor Law and Interpretation. ${ }^{31}$ Significativamente, el fotógrafo que hizo la toma es Joseph Raz, él mismo un destacado filósofo del derecho.

Para concluir, mi propósito al analizar estas imágenes no fue solamente poner en evidencia que durante varios siglos la autoridad, ya sea espiritual, política o judicial, estaba justificada a través de Dios. Mi propósito ha sido más bien mostrar cómo el lenguaje icónico ha sido un medio poderoso para construir una imagen mental del derecho que se ha interiorizado. Esta imagen presente de manera permanente en el discurso público transmite la idea de la trascendencia del derecho, le llamemos Dios, Cristo, justicia, voluntad general, o lo que sea. Y es, la creencia en lo que propuse llamar "el argumento trascendental de legitimidad", el fundamento de nuestra aceptación de la autoridad del derecho en la cultura occidental. Reconstruyéndolo éste dice: Al ser el derecho el medio para realizar la voluntad de Dios o el bien de la comunidad, trasciende los intereses inmediatos de los individuos. Así, este análisis nos llevó por una parte a iden- 
tificar la naturaleza trascendental de la pretensión del derecho a su legitimidad y, por otra, a identificar el mensaje implícito presente en su iconografía, mismo que contribuye a la aceptación de la creencia en la obligación de obedecer el derecho. 